Corpos, sexualidade, diversidade Silvia Alonso, Daniele M. Breyton, Helena, M. F. M. Albuquerque, L. Catocci (Orgs.) São Paulo, SP: Escuta, 2016, 424 págs.

\title{
Passos e impasses nas questões das novas formas de sexualidade
}

Steps and impasses in the new forms of sexuality

A pluralidade é o eixo central do livro resultante da reunião de trabalhos apresentados na III Jornada Temática do grupo do Feminino, do Departamento de Psicanálise do Instituto Sedes Sapientiae com o mesmo título.

Desde o início o leitor é convidado a deslizar entre os campos da psicanálise e de fora dela na tematização das novas sexualidades, do feminismo se encarnando na cultura, na eterna questão da mulher-corpo e, sobretudo, do corpo como suporte da revolução ética, estética e política que acontece na atualidade. Em outra perspectiva, alguns capítulos dedicam-se a trabalhar os efeitos na clínica desse atravessamento.

${ }^{* 1}$ Instituto Sedes Sapientiae (São Paulo, SP, Brasil). 
Sendo o livro uma coletânea, seria impossível abarcar a extensão polifônica que os diversos autores entoaram nas suas reflexões. A variedade da matéria explorada impõe uma complexidade na tarefa de apresentar uma síntese à altura porque são muitos os desdobramentos que essa tríade permite na teorização. A cada tema acrescente-se o plural como flexão gramatical para referir-se ao que não cabe mais no singular, nem no binarismo de gênero estabelecido pela cultura. O mosaico, técnica de criação artística, poderia funcionar como metáfora para a figuração da sexualidade se fosse imaginado como obra inacabada. A identidade de gênero é composta por um grande número de peças que vão se encaixando/desencaixando para formar um desenho único, mas não imutável.

O livro é um retrato fiel da produção intensa que se apresentou no dia do evento. Dessa forma, o leitor acessa a conferência de abertura, a cargo de Silvia Alonso, idealizadora do grupo de trabalho "O feminino e o imaginário cultural contemporâneo" que já completa 20 anos; cada um dos trabalhos apresentados nas 10 mesas, e ainda a transcrição do debate que fechou a jornada, em torno do documentário De gravata e unha vermelha, dirigido por Miriam Chnaiderman.

Sintonizados com as inquietações contemporâneas, os temas convidam a pensar sobre os desfechos possíveis nos processos de subjetivação, considerando-se que tantas forças antagônicas operam como cisão no sujeito e no éthos. A ascensão de formas totalitárias de poder, os discursos de ódio contra tudo que não é espelho e o fundamentalismo religioso, por exemplo, são confrontados com a irrefreável revolução dos corpos trans, com o questionamento de estereótipos de gênero, com a luta por conquista de direitos sociais e outras tantas questões que a atualidade impõe na forma de "in-submissões" contra o estabelecido. Paradoxos que geram conflitos que encontram saída na formação de compromisso através dos sintomas individuais e coletivos que fazem parecer que nunca estivemos tão conectados e ao mesmo tempo tão solitários. Fronteiras e muros vão sendo desenhados para garantir a ilusão de certa proteção contra o que desassossega.

Alguns autores contemporâneos receberam destaque pela afinidade com o tema: Robert Stoller, Judith Butler, Nathalie Zaltzman, Monique Schneider, Silvia Bleichmar, Paul (Beatriz) Preciado e outros.

A psicanálise vai para o divã em alguns textos, pois é repensada em relação ao que permanece na teoria e o que exige o reconhecimento de novos paradigmas, a partir das mudanças na cultura. Como fazer aproximações e distinções entre os vários campos de pesquisa do tecido social, sem perder 


\section{RESENHAS BIBLIOGRÁFICAS}

a especificidade própria à investigação das formações do inconsciente? As pontas do que poderia ser um emaranhado vão entrelaçando fios pela arte, pela política, pelas novas configurações familiares e muito mais.

$\mathrm{O}$ conceito de gênero foi sendo absorvido pela psicanálise, na medida em que permite uma ampliação da teorização sobre a sexualidade superando a indisposição nascida na concepção de que o gênero reside no território do ego. Diversos autores buscaram uma metabolização da contribuição da antropologia para a ampliação dos conceitos de identificação e de gênero.

A teoria psicanalítica ocupou-se, nos últimos tempos, em desvendar os enigmas da feminilidade a partir de diversas releituras sobre as proposições freudianas que, a partir dos anos 1920 tornaram-se falocêntricas, destacando a inveja do pênis e a falta como marcadores do feminino. Ao ocupar um necessário lugar ao sol, esse debate acabou por levar a um encobrimento dos interrogantes acerca da masculinidade, tendo por consequência uma espécie de simplificação sobre o devir masculino. Passou a ser necessário ampliar a temática do feminino para um território múltiplo e amplificado contemplando as novas questões identitárias.

Tal fio condutor segue a partir da ideia de que anatomia não é destino. Porém, faz pensar sobre: Qual seu papel na constituição do sujeito? Se não é ponto de chegada, haveria como escapar da anatomia como ponto de partida? $\mathrm{O}$ que pensa a psicanálise sobre a neutralidade de gênero na educação e na constituição da subjetividade? O binarismo dos gêneros pode ser contestado, mas a metapsicologia psicanalítica não abre mão da dualidade como força motriz do desejo e da irredutibilidade do conflito. Considerando-se que a diferença entre os sexos é um ordenador simbólico na teoria psicanalítica, como fazer caber os sujeitos com atributos masculinos e femininos no mesmo corpo? A ideia de não interdito, não castrado pode conduzir a uma patologização no lugar do entendimento desse ato performativo como conciliador de traços híbridos que constituem todos os sujeitos. Essa figuração viria a abolir a diferença entre os sexos como meio de disfarçar o que sempre falta? Cabe ao psicanalista cuidar para não sustentar uma posição conservadora e preconceituosa sob o manto de sua teoria. Ao sujeito, por outro lado, não cabe nada além de trégua temporária para seus conflitos, pois a pulsionalidade sempre manterá uma dinâmica de desequilíbrio de forças para que a vida siga. Valem as palavras do escritor maior:

O senhor mire, veja: o mais importante e bonito, do mundo, é isto: que as pessoas não estão sempre iguais, ainda não foram terminadas - mas que elas vão sempre mudando. Afinam e desafinam, verdade maior. É o que a vida me ensinou. Isso que me alegra montão. (Guimarães Rosa, 2006, p. 23) 
O apoio no corpo como fonte pulsional, bem como o próprio conceito de pulsão afastam a sexualidade humana da pré-orientação instintual. O objeto da pulsão é contingente e resultante de uma história única feita de marcas deixadas pela presença do outro. Somos, portanto, (in)definidos a partir da orientação por onde segue o desejo e, nesse sentido, "existiriam tantos sexos quanto sujeitos" e a identidade de gênero seria um processo contínuo, interminável.

O livro provoca um desassossego necessário para garantir tal ética psicanalítica nesses nossos tempos. Esse é, sem dúvida, um dos seus grandes méritos.

\section{Referência}

Guimarães Rosa, J. Grande Sertão: veredas. Rio de Janeiro, RJ: Nova Fronteira, 2006.

Citação/Citation: Bento, S. (2018, junho). "Sobre um lido jornal, dorme um corpo desigual. Igual". Resenha do livro Corpos, sexualidades, diversidade. Revista Latinoamericana de Psicopatologia Fundamental, 21(2), 395-398. http://dx.doi.org/10.1590/1415-4714.2018v21n2p395.11

Editores do artigo/Editors: Profa. Dra. Sonia Leite e Profa. Dra.Marta Regina de Leão D’Agord

Recebido/Received: 17.1.2018 /1.17.2018 Aceito/Accepted: 15.3 .2018 / 3.15.2018

Copyright: (C) 2009 Associação Universitária de Pesquisa em Psicopatologia Fundamental/ University Association for Research in Fundamental Psychopathology. Este é um artigo de livre acesso, que permite uso irrestrito, distribuição e reprodução em qualquer meio, desde que o autor e a fonte sejam citados / This is an open-access article, which permits unrestricted use, distribution, and reproduction in any medium, provided the original authors and sources are credited.

\section{Soraia Bento}

Psicóloga, Psicanalista, Professora do curso Clínica Psicanalítica: Conflito e Sintoma do Instituto Sedes Sapientiae, Membro do Departamento de Psicanálise do Instituto Sedes Sapientiae.

soraiabento@icloud.com

\section{(cc) BY-NC}

This is an open-access article, which permits unrestricted use, distribution, and reproduction in any medium for non-commercial purposes provided the original authors and sources are credited. 